\title{
Inserting ex vivo Fluorescence Confocal Microscopy Perioperatively in Mohs Micrographic Surgery Expedites Bedside Assessment of Excision Margins in Recurrent Basal Cell Carcinoma
}

\author{
Caterina Longo $^{a}$ Moira Ragazzi ${ }^{b}$ Fabio Castagnettic Stefano Gardini ${ }^{\mathrm{a}}$ Tamara Palmieri ${ }^{\mathrm{d}}$ \\ Aimilios Lallas $^{a}$ Elvira Moscarella ${ }^{a}$ Simonetta Piana ${ }^{b}$ Giovanni Pellacani ${ }^{\mathrm{e}} \quad$ Iris Zalaudek ${ }^{a}$ \\ Giuseppe Argenziano ${ }^{a}$ \\ ${ }^{a}$ Skin Cancer Unit, ${ }^{b}$ Pathology Unit, c Surgery Unit and d Radiotherapy Unit, Arcispedale Santa Maria Nuova-IRCCS, and \\ eDepartment of Dermatology, University of Modena and Reggio Emilia, Reggio Emilia, Italy
}

\section{Key Words}

Basal cell carcinoma Confocal microscope

\begin{abstract}
Mohs micrographic surgery can be employed in recurrent basal cell carcinoma, although it is a time-consuming technique. Recently, ex vivo fluorescence confocal microscopy (FCM) has been employed to obtain a fast assessment of tumor margins at the bedside. In our case we successfully employed ex vivo FCM to assess the tumor margins and we treated the persistent tumor with intensity-modulated radiation therapy. Our case demonstrates that a multidisciplinary approach is very efficient in managing complex and recurrent tumors and highlights the benefits of FCM as a new technique that can be used in the surgical theater to speed up the entire procedure.
\end{abstract}

(c) 2013 S. Karger AG, Basel

\section{Introduction}

Basal cell carcinoma (BCC) is the most common skin malignancy often occurring on sun-exposed and cosmetically sensitive areas such as the face. Many therapeutic options are available and the choice is strongly dependent on the body site location, histological type, size of the tumor and patient comorbidities.

In case of recurrent BCC, especially in the case of infiltrative types, surgery is regarded as a first-line option. Mohs micrographic surgery can be employed in specialized centers to obtain complete margin control during the excision of the lesion [1, 2]. The major limitation of this method is the time needed to perform multiple consecutive excisions and the time required to obtain the histological report of the examined frozen sections.

In vivo confocal microscopy has been used for margin assessment of tumors before surgery, although its use is limited to the exploration of lateral margins and not of the deep tumoral area.

Recently, ex vivo fluorescence confocal microscopy (FCM) has been employed as an innovative tool that can provide a fast imaging of the fresh tissue with no need of any staining or special sample preparation that may require a dedicated laboratory technician [3-16]. Compared to in vivo confocal microscopy, FCM permits the analysis of freshly excised tumor allowing the assessment of deep margins with higher resolution because of the employment of fluorescent agent contrast.

Herein, we report a case of recurrent BCC that has been subjected to FCM for margin control.

\section{Case Report}

An 84-year-old man was referred for the presence of a subcutaneous nodule located on the left cheek. A punch biopsy revealed a BCC and, since 5 years earlier the patient had undergone surgical excision of a BCC in the same area, the lesion was regarded as a recurrent BCC.

Clinically, the nodule was firm and sized $1.5 \times 2.5 \mathrm{~cm}$. Dermoscopic examination revealed the presence of a central yellowish crust surrounded by small erosions. Since the lesion was mostly located deeply in the dermis, the classic dermoscopic findings such as arborizing vessels and other specific diagnostic features were lacking (fig. 1). Moreover, it was not possible dermoscopically to clearly define the margins of the tumor.

\section{KARGER}

E-Mail karger@karger.com

www.karger.com/drm
(C) 2013 S. Karger AG, Base

$1018-8665 / 13 / 2271-0089 \$ 38.00 / 0$
Caterina Longo, $\mathrm{MD}, \mathrm{PhD}$

Dermatology and Skin Cancer Unit, Arcispedale Santa Maria Nuova Viale Risorgimento, 80 IT-42100 Reggio Emilia (Italy)

E-Mail longo.caterina @ gmail.com 

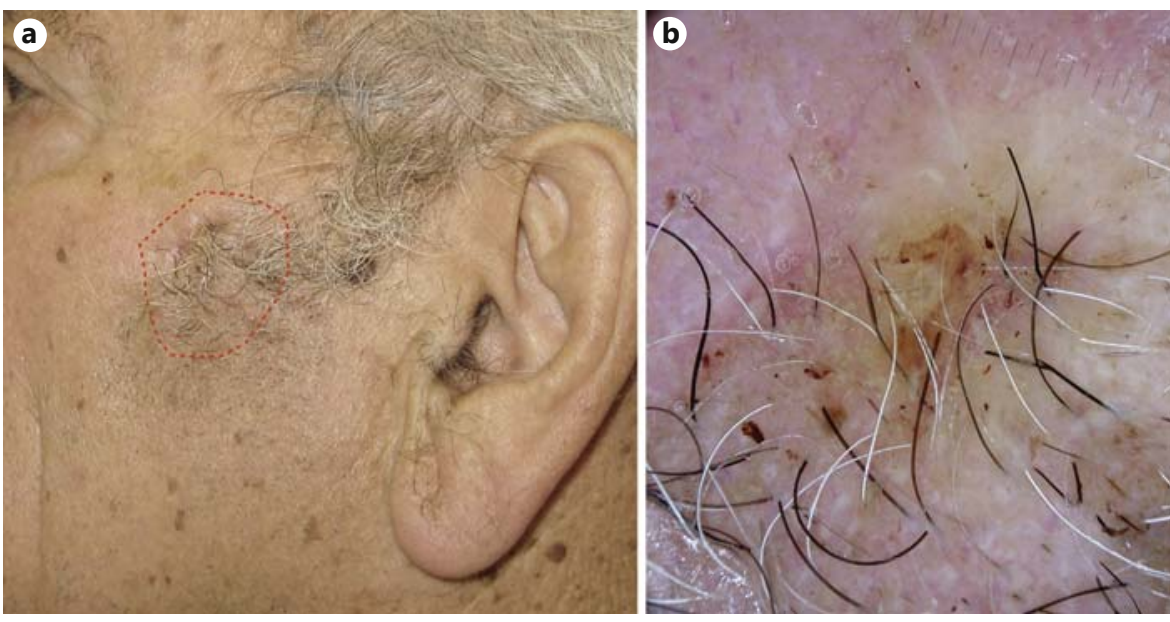

Fig. 1. a Clinical view of a firm, poorly defined nodule (dashed lines), sized $1.5 \times 2.5 \mathrm{~cm}$ and located on the left zygomatic process. $\mathbf{b}$ Dermoscopy reveals the presence of a yellowish crusted area surrounded by small erosions.
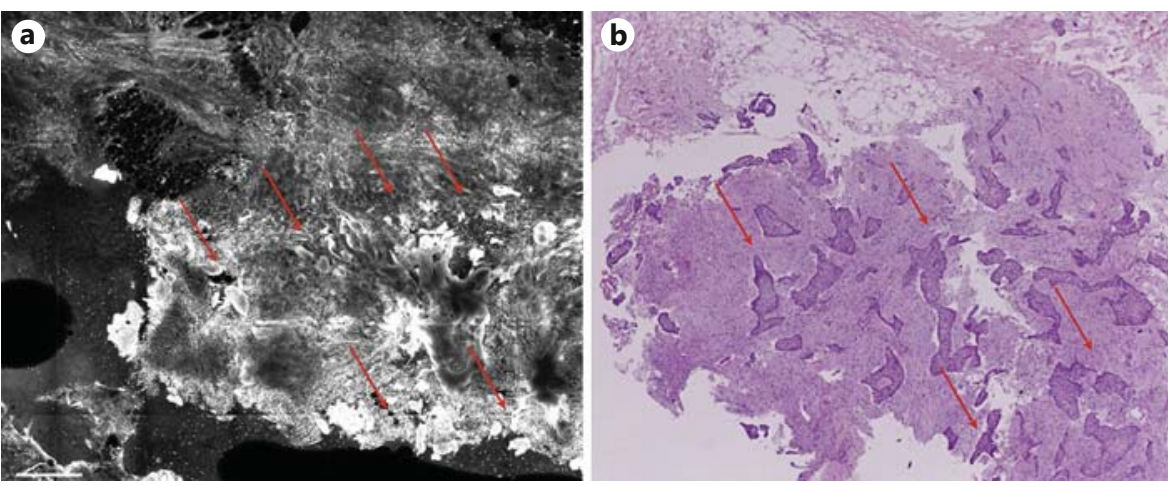

Fig. 2. a FCM image of the bottom area of the lesion reveals the presence of highly fluorescent structures (arrows) reaching the lowest margin. Scale bar $=500 \mu \mathrm{m}$. b The histological examination shows basaloid islands infiltrating and occupying the bottom of the tissue (arrows). Original magnification $\times 20$.
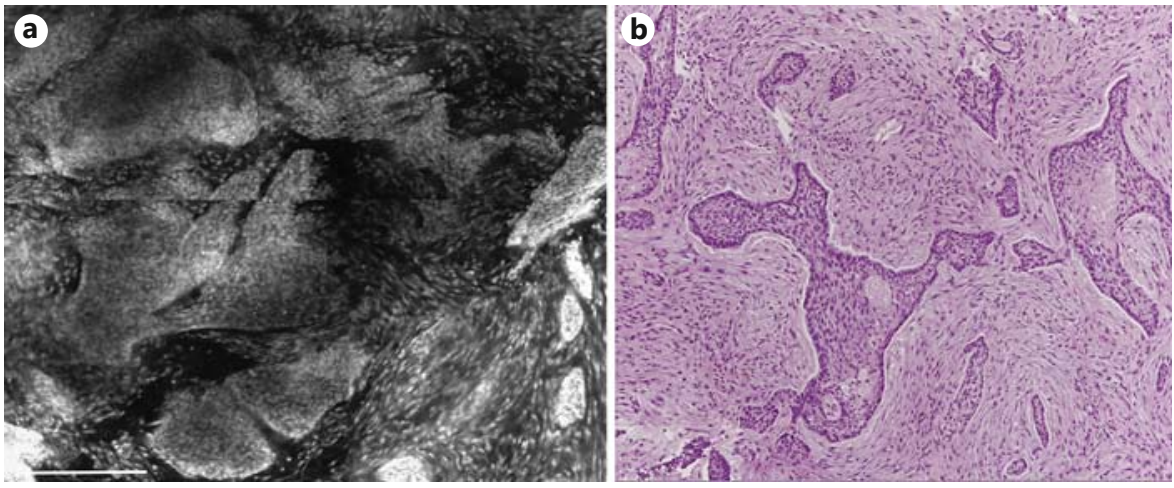

Fig. 3. a On FCM, basaloid islands are typified as fluorescent nests variable in size and shape with jagged contours and abortive palisading. Scale bar $=200 \mu \mathrm{m}$. b The histology depicts an infiltrative BCC characterized by basaloid cords and nests that are well correlated with the ones seen upon FCM. Original magnification $\times 40$.
The lesion was excised under local anesthesia using the Mohs surgery procedure. No surgical debulking was performed. The excised tissue was sliced into different sections to evaluate the margins using the square procedure. Each skin tissue was examined by means of a commercially available laser scanning fluorescence confocal microscope (Vivascope ${ }^{\circledR} 2500$; CaliberID, Rochester, N.Y., USA.). Briefly, the tissue was immersed in a $0.6-\mathrm{mM}$ solution of acridine orange dye for 10-20 s, and then the excess of staining dye was removed by wiping with paper. In this way, blood was also removed. The tissue, oriented on the cut side, was placed onto the microscope and digital mosaics were acquired as described elsewhere [3, 4]. The time needed to acquire all samples was about 9 min.

On FCM, the examined skin tissues revealed complete clearance on the lateral margins; however, the periostium was shown to be infiltrated by the tumor. Basaloid cells appeared highly fluorescent compared to the surrounding stroma, although they were not clearly demarcated (fig. 2). There were jagged and infiltrative fluorescent basaloid cords with absence of clefting and abortive palisading. These cords were located at the bottom of the analyzed tissue, and thus the margin was assessed as positive. Frozen-stained sections that were cut to confirm the FCM findings revealed an infiltrative BCC. An excellent correlation was found between FCM and histological aspects (fig. 3).

Since the excision was performed under local anesthesia, no further excisions of the periostium and bone were possible and the defect was closed using a local flap. The patient was informed about the persistence of the tumor, but he refused further surgical procedures.

Considering the lesion location and the patient age and willingness, our multidisciplinary team proposed to perform intensity-modulated radiation therapy (IMRT) [17-19] to treat the persistent tumor and to spare organs at risk located in the proximity of the tumor.

The treatment was carefully planned using 3-dimensional computed tomography images of the patient in conjunction with computerized dose calculations to determine the dose intensity pattern that would best conform to the tumor shape (fig. 4). Typically, combinations of multiple intensity-modulated fields coming from different beam directions produce a 
custom tailored radiation dose that maximizes tumor dose while minimizing the dose to adjacent normal tissues. A medical linear accelerator was used. The radiation dose for each session was $300 \mathrm{~Gy}$ daily for 5 days per week for a total of 3 weeks.

After a 4-month follow-up, there were no signs of persistence of the tumor from a clinical and radiological point of view.

\section{Discussion}

BCC recurrences represent a serious therapeutic problem in clinical practice. Most recurrences occur within 3 years following the first surgical treatment, but approximately $20 \%$ appear between 6 and 10 years after excision [20]. Tumors of the head and neck area are at higher risk for recurrence and the prognosis in such areas can be worse due to the frequent extensive subclinical spread of the lesion. Mohs micrographic surgery is the best treatment modality for such lesions, but it is a timeconsuming technique. Recently, ex vivo FCM has been applied as a promising method to overcome these obstacles. FCM provides a fast intraoperative diagnosis of a given tissue with excellent histological details, at the patient's bedside without employing a dedicated laboratory of pathology but just using a staining (acridine orange) that in few seconds provides a good contrast of cell nuclei and, thus, a fast reading for the Mohs surgeon.

Our patient had a recurrent BCC that appeared as a subcutaneous nodule with indistinct margins. The use of FCM allowed us to detect, in less than $9 \mathrm{~min}$, the tumoral involvement of the deep excisional margin with an excellent histological correlation. Moreover, the histological infiltrative type of the lesion was clearly recognized, despite the diagnostic difficulties related to its tiny cords that can be masked by an overwhelming stroma.

Because of the patient's age and his unwillingness to perform additional surgery involving the bone, an IMRT was proposed by our multidisciplinary team. IMRT is an advanced mode of high-precision radiotherapy that uses computer-controlled linear accelerators to deliver precise radiation doses to a given tumor. It allows for the radiation dose to conform more precisely to the 3-dimensional shape of the tumor by modulating the intensity of the radiation beam in multiple small volumes. More-
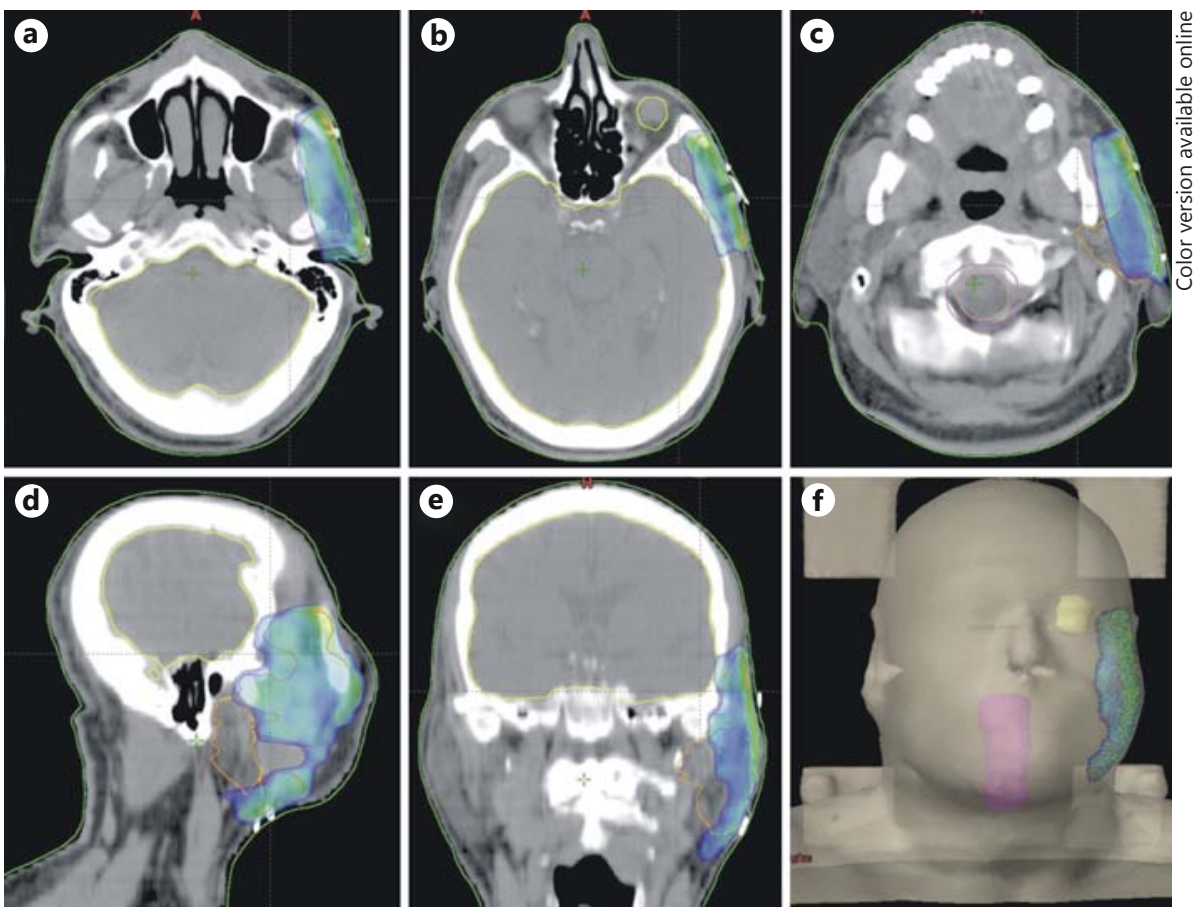

Fig. 4. Three-dimensional computed tomography images showing the tumor area (a), and the organs at risk that are depicted by a thick solid line: eye (b, yellow), parotid glands (orange) and pituitary gland (c, pink). d Sagittal plane. e Coronal plane. $\mathbf{f}$ Rendering of the area highlighting the dose distribution. Colors refer to the online version only.

over, IMRT allows higher radiation doses to be focused preferentially to the tumor while minimizing the dose to surrounding normal critical structures that are thus spared.

Our case demonstrates that a multidisciplinary approach is very efficient in managing complex and recurrent tumors and highlights the benefits of FCM as a new technique that can be used in the surgical theater to speed up the entire procedure.

\section{Acknowledgment}

The study was supported in part by the Italian Ministry of Health (RF-20102316524).

\section{Disclosure Statement}

The authors have no conflict of interest to declare.

\section{References}

1 Mohs FE: Chemosurgery: Microscopically Controlled Surgery for Skin Cancer. Springfield, Thomas, 1978.

-2 Mosterd K, Krekels GA, Nieman FH, et al 'Surgical excision versus Mohs' micrographic surgery for primary and recurrent basal-cell carcinoma of the face: a prospective randomised controlled trial with 5-years' followup. Lancet Oncol 2008;9:1149-1156.

-3 Rajadhyaksha M, Menaker G, Flotte T, Dwyer PJ, González S: Confocal examination of nonmelanoma cancers in thick skin excisions to potentially guide Mohs micrographic surgery without frozen histopathology. J Invest Dermatol 2001;117:1137-1143.

-4 Chung VQ, Dwyer PJ, Nehal KS, Rajadhyaksha M, Menaker GM, Charles C, Jiang SB: Use of ex vivo confocal scanning laser microscopy during Mohs surgery for nonmelanoma skin cancers. Dermatol Surg 2004;30:1470-1478.

5 Patel YG, Nehal KS, Aranda I, Li Y, Halpern AC, Rajadhyaksha M: Confocal reflectance mosaicing of basal cell carcinomas in Mohs surgical skin excisions. J Biomed Opt 2007;12: 034027. 
6 Gareau DS, Patel YG, Li Y, Aranda I, Halpern AC, Nehal KS, Rajadhyaksha M: Confocal mosaicing microscopy in skin excisions: a demonstration of rapid surgical pathology. J Microsc 2009;233:149-159.

-7 Schüle D, Breuninger H, Schippert W, Dietz $\mathrm{K}$, Moehrle M: Confocal laser scanning microscopy in micrographic surgery (three-dimensional histology) of basal cell carcinomas. Br J Dermatol 2009; 161:698-700.

-8 Ziefle S, Schüle D, Breuninger H, Schippert W, Moehrle M: Confocal laser scanning microscopy vs 3-dimensional histologic imaging in basal cell carcinoma. Arch Dermatol 2010; 146:843-847.

-9 Yaroslavsky AN, Barbosa J, Neel V, DiMarzio C, Anderson RR: Combining multispectral polarized light imaging and confocal microscopy for localization of nonmelanoma skin cancer. J Biomed Opt 2005;10:14011.

10 Al-Arashi MY, Salomatina E, Yaroslavsky AN: Multimodal confocal microscopy for diagnosing nonmelanoma skin cancers. Lasers Surg Med 2007;39:696-705.

11 Gareau DS, Li Y, Huang B, Eastman Z, Nehal KS, Rajadhyaksha M: Confocal mosaicing microscopy in Mohs skin excisions: feasibility of rapid surgical pathology. J Biomed Opt 2008; 13:054001.
12 Gareau DS, Karen JK, Dusza SW, Tudisco M, Nehal KS, Rajadhyaksha M: Sensitivity and specificity for detecting basal cell carcinomas in Mohs excisions with confocal fluorescence mosaicing microscopy. J Biomed Opt 2009; 14:034012.

13 Karen JK, Gareau DS, Dusza SW, Tudisco M, Rajadhyaksha M, Nehal KS: Detection of basal cell carcinomas in Mohs excisions with fluorescence confocal mosaicing microscopy. $\mathrm{Br}$ J Dermatol 2009;160:1242-1250.

14 Bennàssar A, Vilalta A, Carrera C, Puig S, Malvehy J: Rapid diagnosis of two facial papules using ex vivo fluorescence confocal microscopy: toward a rapid bedside pathology. Dermatol Surg 2012;38:1548-1551.

15 Abeytunge S, Li Y, Larson B, Toledo-Crow R, Rajadhyaksha M: Rapid confocal imaging of large areas of excised tissue with strip mosaicing. J Biomed Opt 2011;16:050504.

16 Abeytunge S, Li Y, Larson B, Peterson G, Seltzer E, Toledo-Crow R, Rajadhyaksha M: Confocal microscopy with strip mosaicing for rapid imaging over large areas of excised tissue. J Biomed Opt 2013;18:61227.
7 Buettner F, Miah AB, Gulliford SL, Hall E, Harrington KJ, Webb S, et al: Novel approaches to improve the therapeutic index of head and neck radiotherapy: an analysis of data from the PARSPORT randomised phase III trial. Radiother Oncol 2012;103:82-87.

8 Nutting CM, Morden JP, Harrington KJ, Urbano TG, Bhide SA, Clark C, et al, PARSPORT trial management group: Parotid-sparing intensity modulated versus conventional radiotherapy in head and neck cancer (PARSPORT): a phase 3 multicentre randomised controlled trial. Lancet Oncol 2011;12:127123.

19 Holt A, Van Gestel D, Arends MP, Korevaar EW, Schuring D, Kunze-Busch MC, Louwe RJ, van Vliet-Vroegindeweij C: Multi-institutional comparison of volumetric modulated arc therapy vs intensity-modulated radiation therapy for head-and-neck cancer: a planning study. Radiat Oncol 2013;8:26.

20 Santiago F, Serra D, Vieira R, Figueiredo A: Incidence and factors associated with recurrence after incomplete excision of basal cell carcinomas: a study of 90 cases. J Eur Acad Dermatol Venereol 2010;24:1421-1424. 